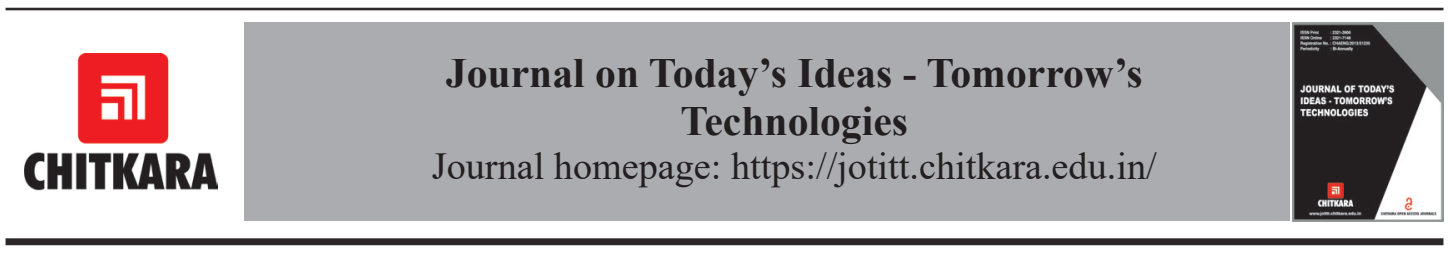

\title{
Coping of Off-campus Class during the COVID-19 Crisis for the Architecture Pedagogy in Bangladesh
}

\author{
Masud Ur Rashid \\ Department of Architecture, Southeast University, Dhaka-1208, Bangladesh \\ Email: masudurrashid@yahoo.com
}

ARTICLE INFORMATION

Received: April 10, 2020

Revised: June 26, 2020

Accepted: June 27, 2020

Published online: December 03, 2020

Keywords:

Off-campus class, COVID-19, Architecture pedagogy, Tertiary education in Bangladesh

\begin{abstract}
Many of the private universities of Bangladesh have decided to continue their academic activities through online off-campus learning amid concerns that traditional classes could spread the COVID-19 virus. Teaching is moving online, on an untested and unprecedented scale. There are challenges and possibilities unveiling in the technical tertiary level education like Architecture. A Bachelor of Architecture (B.Arch) programme need to be comprising of both theory and sessional studio courses. The learning modes are not same for these two areas. Modification and new invention of teaching methods need to be introduced to coping of off-campus class. In this study, the first-hand experience of on-line teaching in B.Arch program of the author and the similar experience of faculties of the different universities of Bangladesh are triangulated to come up with a model of off-campus class. This article finds out the systematic process of teaching method to coping of off-campus class during the COVID-19 crisis for the Architecture pedagogy. The process has three domains and four major areas. The teacher's domain and the student's domain are connected through the domain of virtual classroom. The four major areas are live streaming, live discourse, prerecorded lecture and assignment and feedback. A well synchronization of these areas can establish the model of off-campus class for architecture pedagogy.
\end{abstract}

\section{Introduction}

COVID-19 is a pandemic that shows how interconnected we are worldwide - there is no longer anything about discrete problems and behaviour. The COVID-19 pandemic is a health issue, in the first place. Most governments have agreed (rightly) to shut down schools, colleges, and universities. Many households around the world experience the extreme short-term disruption: home schooling is not only a huge blow to the prosperity of the community, but also to the social life and learning of the children [1]. Teaching moves online on an untested and unimaginable size. Student tests often pass electronically, with a lot of trial and error and confusion for both [2].

The COVID-19 pandemic led to educational institutions worldwide being forced to unexpectedly exploit and use the suite of available technical resources to create material for students in all sectors for remote learning. Educators around the world are finding new 
ways of doing it better and with greater versatility resulting in future gains for students worldwide through openness to education. These are new modes of instruction that have previously been largely untapped particularly in formal education [3]. Some research shows that on average, students retain $25-60 \%$ more material when learning online compared to only $8-10 \%$ in a classroom. This is mostly due to the students being able to learn faster online; e-learning requires $40-60 \%$ less time to learn than in a traditional classroom setting because students can learn at their own pace, going back and re-reading, skipping, or accelerating through concepts as they choose [4].

For the intent of $21^{\text {st }}$ century schooling, the notion of an instructor as the knowledgeholder who imparts insight to their pupils is no longer suitable. With students having access to information and even acquiring a technological ability, we would need to redefine the role of the instructor in the classroom and lecture theatre by tapping on their phones, tablets and computers. This may mean that educators' position would have to shift towards promoting the development of young people as active members of society.

Many universities of Bangladesh have started teaching online in the face of concerns that conventional classes could spread the corona virus. Migrating courses online has been one of the approaches many colleges accept. To have the teaching staff, students and facilities ready for lessons to transition smoothly into online learning, so much historical planning had to be completed. Although versatility was required to ensure diverse learning outcomes in different programmes could be accomplished, continuity across universities was crucial in this period of crisis.

\section{Background}

There are challenges and possibilities unveiling in the technical tertiary level education like Architecture. The Bachelor of Architecture (B.Arch.) programme involves a wide range of disciplines in the fields of arts, sciences and engineering. There are diversified theoretical courses as well as significant number of studio sessions for application of knowledge and understandings to practical design problems.

According to the guideline of Institute of Architects Bangladesh [5], a Bachelor of Architecture (B.Arch) programme need to be comprises of both theory and sessional studio courses. The sessional courses are the $60-65 \%$ of total credit hours. Most of the universities of Bangladesh follow this guideline. The learning mode are not same for these two areas. Theory courses are lecture based learning and sessionals are studio-based exercise mainly focused on design and other supporting skill development.

The B.Arch programme of Southeast University is taken as case study for this article. Southeast University is one of the eleven universities of Bangladesh who run B.Arch programme accredited by the Institute of Architects Bangladesh [6]. It is situated in Dhaka, the capital of Bangladesh. Which is a city of more than 20 million [7] and have the main international airport.

After found few people with COVID-19 positive, the government of Bangladesh ordered a shutdown from the $16^{\text {th }}$ March 2020 of all educational institutes for next two weeks to avoid mass gathering [8]. This shut down period has been extended. As private universities always try themselves to make them free from session jam, many of them decided to continue their academic activities through online offcampus learning. Again off-campus class is not permitted in main-steam tertiary education policy of the government of Bangladesh. So, this is a new challenge for all universities who wanted to start off-campus class.

It was the mid-term of the Spring semester in the Southeast University. Migrating lectures and even faculty-student interaction online is challenging. The most common questions are: "How can we facilitate interactive, student-tostudent learning in an online setting?" and "If 
our courses move online, how do we carry out online assessments without risking cheating and plagiarism?" The university management instruct all the students and faculties to conduct off-campus online class to cope up the present situation and make the students' academic life free from major interruption. Faculties who are always accustomed with lecture and studio based learning required to make themselves prepare for the situation along with the courses. This involves the modification and in some cases new invention of teaching method to coping of offcampus class during the COVID-19 crisis for the Architecture pedagogy.

\section{Methodology}

The main objective of this article is to find out the systematic process of teaching method to coping of off-campus class during the COVID-19 crisis for the Architecture pedagogy. Finding of this study may be helpful for the educators of architecture as well as other technical education of the tertiary level.

The study is done through a qualitative research approach along with some quantities data triangulation. This study is based on both primary and secondary data. Primary data has been collected through the first-hand experience of the author. The experiences are expressed by graphs, charts, screen shot images of personal computer etc. Secondary sources of data are the faculties of the different universities of Bangladesh. Formal interviews and informal discussions are considered as data source for this study. Educators of 8 (eight) different universities of Bangladesh are considered for this. Literature review of authentic sources has been used to have an extensive picture of the COVID-19 scenario over the education system all over the globe.

A social-network based survey has been conducted where 1072 students of different programmes of Southeast University participated spontaneously. Interviews and discussions with more than 100 students of different level of B.Arch programme took place to get the opinions and views about the challenges from the students' end. Moreover, a group discussion of more than 184 teachers of different department was considered to get understanding about their process to coping of off-campus class during the COVID-19 crisis.

The methodology for this research is expressed graphically in Fig. 1.

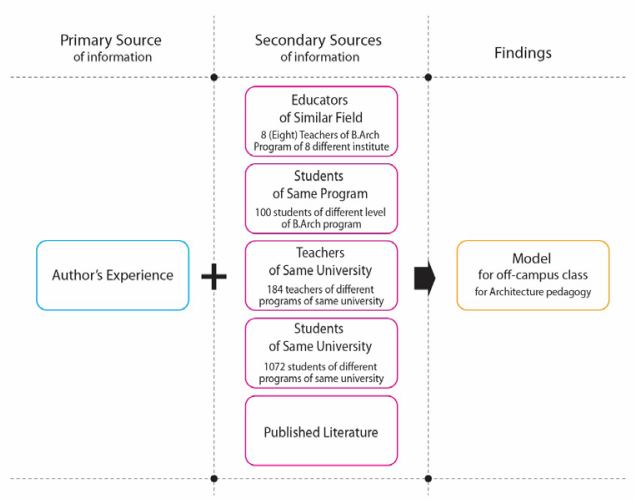

Figure 1: Different sources of information

After analysing all the information and data a model for the off-campus online class has been established. This model has been validated through practical class with the respective students of the course. These students also have taken participation in the model generating process.

Some limitations might be noted regarding the study and analysis. All the interviews, discussion and surveys are conducted through on line and resources from website are used due to maintaining the stay at home of the author. As closing of all the educational institute is a very sudden decision by the government, teachers and students did not take enough time to make themselves prepare for what is coming on. Moreover, COVID-19 patients are found in the families of the sample of this study, these also interrupt the analysis a bit. This research is the first of its kind, so the author did not receive much published reference to use as background. 


\section{Coping of Online Class}

\subsection{Preparing the Students}

Students are the major stakeholder of a class. All the COVID-19 crisis began so fast that students were not pre-noticed and prepared as advance. A survey on social networking platform (Facebook) taken place by the students spontaneously. There were total 1072 students from the different departments of the Southeast University give their opinion regarding the off-campus online class. It is found that 962 students thought that the off-campus class is not a suitable solution during the crisis and only 110 students had positive response towards the off-campus class (Fig. 2). So it was a big challenge for the teachers to motivate their students to make it happen.

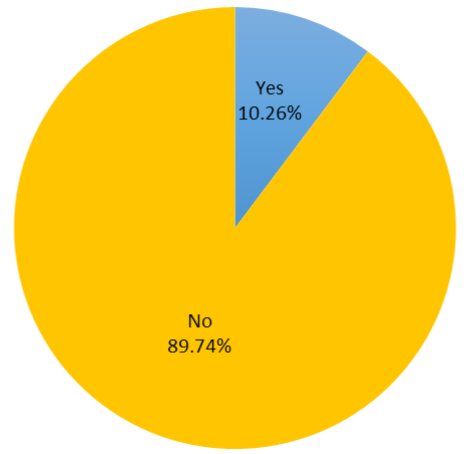

Figure 2: Students opinion regarding the feasibilty of offcampus class

The first challenge is for the teachers to motivate their students to join the class and introduce something easy to cope up for the students. Creating interest towards the class is a vital role for all teachers. This is done through personal tele-communication, using of social networks and texting in Facebook groups of the students and teachers.

To find out the reasons behind the negative feedback to join the online campus a survey was held among the 200 students of the Architecture department of the Southeast University. Result shows that 92 students have five different type of problems to join off-campus class through internet. There are 14 students who do not have any personal computer of laptop, 42 students left their station due to lock-down leaving their personal computer or laptop at their station. As the educational institutes closed suddenly, they were not prepared for such long vacation. 21 students do not have internet access or have very low speed internet that are not suitable to join live streaming class at online. Some of them are not capable to buy that huge amount of internet to join class. 4 students are found who are not in a mental condition to continue regular studies in this pandemic situation and there are 11 students who are afraid to use modern technology (Fig. 3).

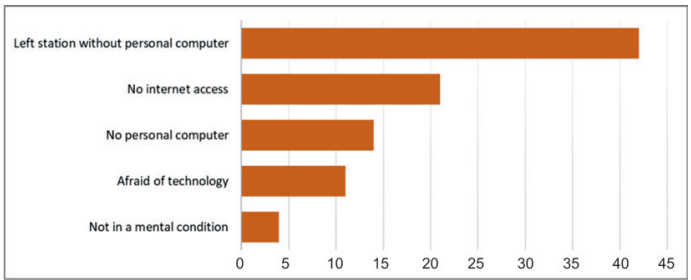

Figure 3: Different problems of the students to join the online classees

Teachers motivation and introduction of technologies in easy ways to make the students understand that they can join the class through their smart phones and low speed internet can help the students to make participate. This can bring a huge number of students in off-campus class. Teachers can make the class concise in duration to attract more students.

\subsection{Maintaining the Learning Outcome}

Flexibility while ensuring accountability is important. Because such evaluations could no longer be performed as expected, alternate approaches were needed to evaluate the same learning outcomes. The degree programme must be recognised and all learning outcomes must then also be accomplished and demonstrated given the contingency measures in place.

Each course and each instructor need to make a decision about the appropriate means in light of the nature of the course. It need to be emphasised that online platforms are 
to be viewed as learning environments, like classrooms and studios, that enabled effective learning to take place. Despite the rush, it is important to engage learners. Many teachers are doing live streaming for the first time, so they're able to face the chances and collect praise for the positive learning outcomes in return.

Rather of asking the students to catch up with what they had missed for their peers, the teachers made plans to ensure they could access the learning material and answer questions. Ensuring they are not losing out on learning is crucial. Having technology on hand to help them join in discussions wherever possible.

\subsection{Introducing Technology}

Although the assumption is that most students have a laptop to do e-learning, there's always a tiny amount who don't. That meant that in the transition from face-to-face to e-learning no one was left behind. A cellular phone can be used as a communication module to join the off-campus class. Communication networks are essential, ensuring that thoughts and observations were exchanged despite not seeing one another physically. The feeling that "we are in this together", or "if I make a mistake in the online learning platform, I am not the only one”, helped to support everyone in the journey [5].

Technology such as Zoom, Google meet and Microsoft Teams was introduced to all teaching staff and students. It allowed teachers to choose what worked best for them and their students. It also required the provision of training and guidance based on available key resources. The key instruments offered continuity so that students did not confuse or rush to learn different instruments (Fig. 4).

Teachers prefer free or paid versions of the most popular video chat. Teachers are continuing their distance learning through live streaming video apps like Hangouts, Hangouts Meet, Zoom, Periscope, Meerkat, Facebook Live, YouTube Live, Skype and more. Google Classroom is a choice for the base platform to communicate and organize the students. Recently the University Grants Commission (UGC) make an arrangement to have On-Premise account of Zoom for the faculties of all universities of Bangladesh. Teachers can take their class with some additional facilities using this account.

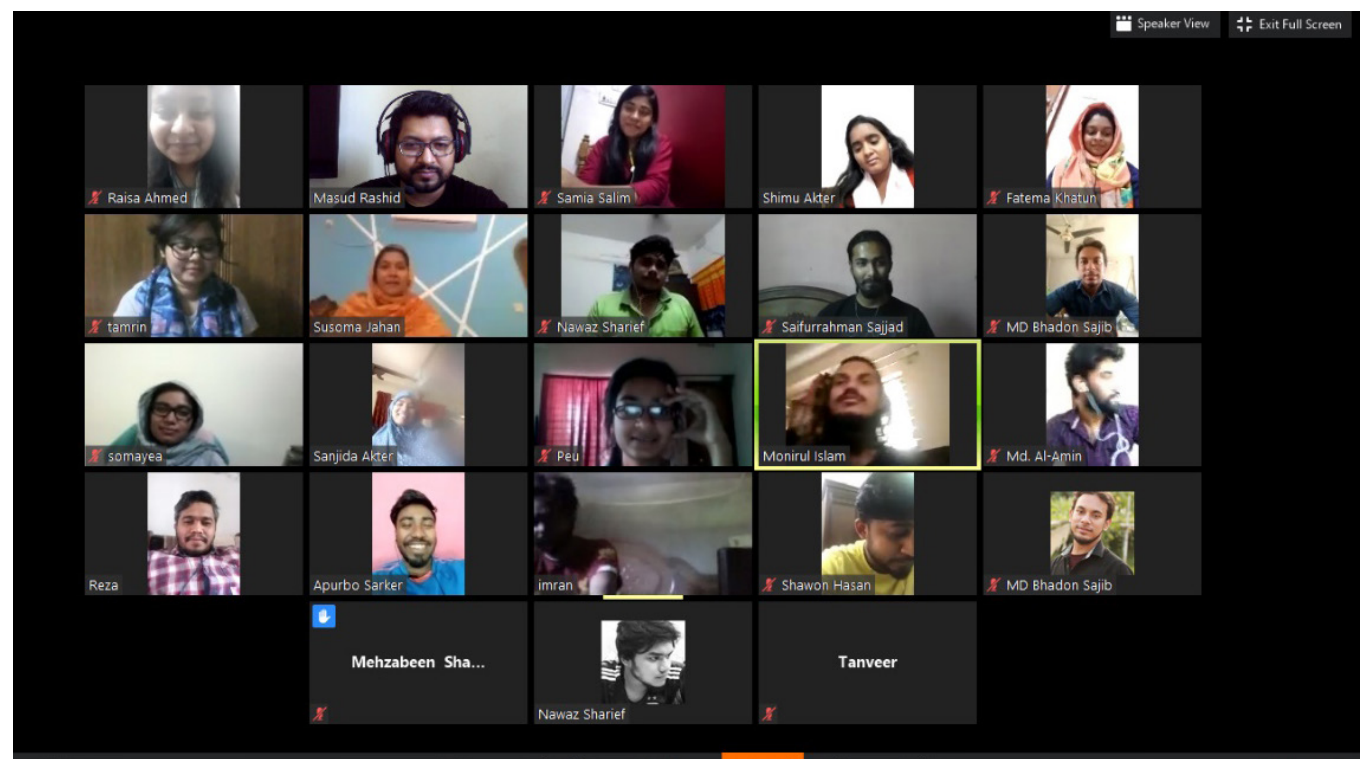

Figure 4: Live discussion in Zoom platform 
There is another challenge to conduct the Design studios and Graphics classes for the lower level students where it is necessary to make them understand many basic things of design and drawings hand to hand. For these courses, teachers need to make tutorial of their deliveries with examples. Teachers need to make video by working with their own hand and drawings on drawing sheets and upload them in virtual classroom drive. These tutorials are recommended to be small in length and file size for the convenience of the students. They need to be uploaded one by one with a synchronisation of the learning outcome. Students can download them and make themselves clear during the live discussion if they feel any confusion. Students can work in home by their hands and take the photographs of their works and drawing sheets and upload them in the virtual classroom for getting the feedback from the teachers' end. Some basic tools like, drawing sheets, pen and pencils, paper for making model etc. are required to perform this stage. Students need to be encouraged for group studies in small groups at their convenient time without the presence of the teacher. Teachers need to be intelligent to select tasks and projects for the students in this pandemic situation.

\subsection{The Model}

A virtual classroom like Google Classroom need is acting as the hub of all communication, reading material storage, students works storage, students' attendance and performances log etc. Google
Classroom, created by Google for schools, is a free online service designed to simplify paperless activities to build, distribute and rate. Google Classroom's primary aim is to streamline the filesharing process between students and teachers.

Google Classroom integrates Google Drive, Google Docs, Sheets and Slides, and the Google Calendar to schedule tasks. Students may be invited to participate by means of a private code or imported from a school domain automatically. The students may send works to be graded to teacher in each class on a separate folder inside the respective user's drive. Mobile apps, available on iOS and Android devices, allow users to take photos and connect to tasks, share data files, and access offline information. Teachers can track progress for each student, and teachers can come back to work with comments.

Fig. 5 shows the relationship among different segment of the model.

A live streaming software need to be used to conduct live class and discourse with the students. Zoom, Hangout, Skype, TeamViewer are such softwares. All of them works in web-based platform both in computer and mobile phone. These are online video-conferencing platform that provides a central, desktop user and a mobile application to meet users with or without a video. Teacher and students can may have live lecture and discussion in this platform. Live streaming has the option of recording the whole discussion with Audio-visual. This audio-visual is to be stored at the virtual Classroom for the students who

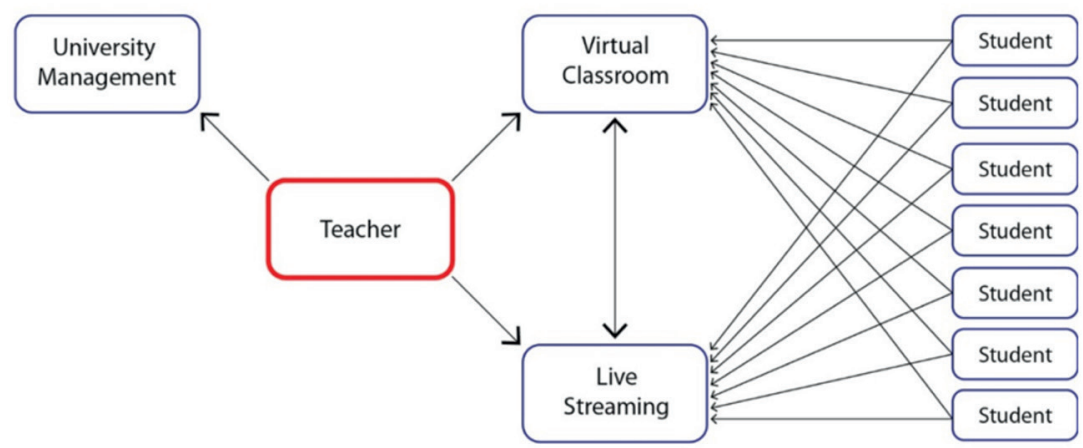

Figure 5: Communication model for an off-campus class 
did not participating the live session. Students have poor internet connection may also access the audio-visual file anytime.

Live video can be saved in internetbased Free Services (Free Facebook); Low end Android mobile-based built-in apps e.g. Hangouts, Imo etc. So that the next viewing apps like Facebook Live, YouTube Live; Considering the variety of technologies, including Google's secure G-suite package, with almost all the benefits, a simpler and more realistic solution will come out.

Teacher need to report to the university management, monitoring team or to the chairperson of the programme about the class, its performance and attendance. A standard reporting format may be used to ensure the convenience for both parties.

The process of off-campus class basically has three domains. They are the teacher's domain, the student's domain and the virtual classroom (Fig. 6). The teacher's domain and the student's domain are connected through the Virtual classroom. These three are the three vital parts of the whole system. All of them has storage facilities for soft files. From teacher's end, he/she need to upload the reading materials for both theory and sessional courses at the virtual classroom. Sometimes pre-recorded lectures or sessional brief may also be uploaded. From student's end they downloaded the materials for reading or as reference for their exercise. Besides, teacher can assign specific work to the students. Students do that work in offline mood with the help of various softwares. AutoCAD, SketchUp and Revit are the most popular software for basic architectural works to the students. In some cases, students upload image of their sketches to the virtual class room. Teacher collects all the submissions form the classroom drive and arrange a live discussion using a live streaming software sharing his/ her computer screen.

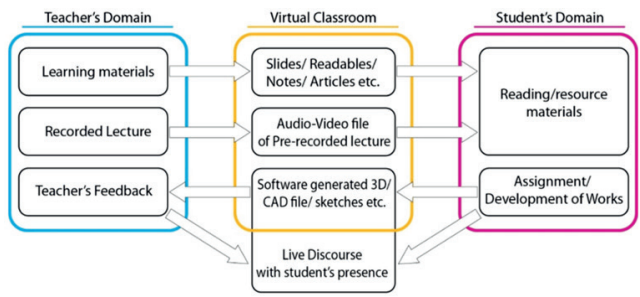

Figure 6: Interaction of different domain of the off-campus class model

In some cases, students can share their screen to show the work and receives comment from the teacher (Fig. 7). A live discourse on student's work takes place connecting both the teacher's and student's domain. This discourse is recorded at the teacher's end and later it is uploaded to the virtual classroom as a reference material for all students.

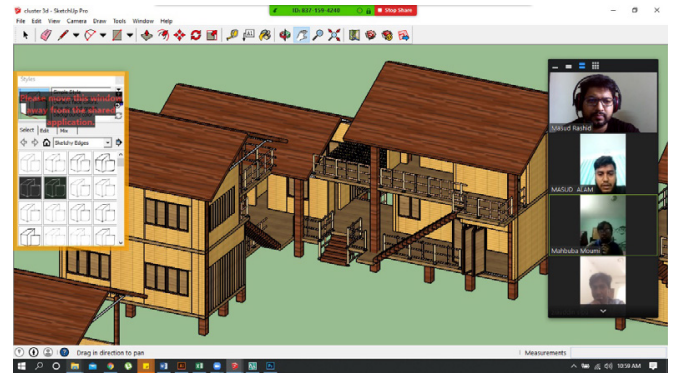

Figure 7: Live discourse for student's work

A live lecture is required to conduct a theory class as well as for sessional studio. For a live lecture, it is preferable that teacher need to play the relevant slides and share his/her screen at the live streaming platform (Fig. 8). Again the whole lecture need to be recorded and uploaded to the classroom to make the maximum students beneficiary.

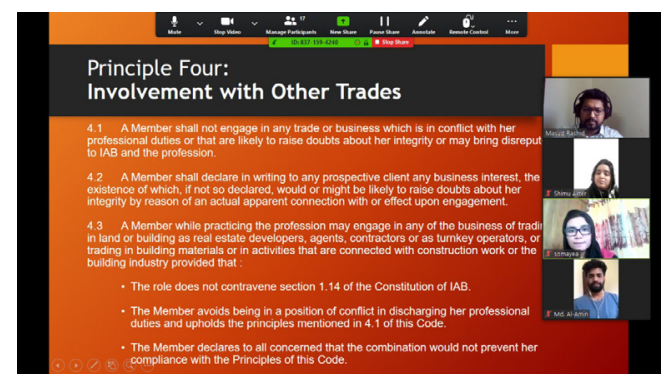

Figure 8: Live streaming of lecture for a theory course 
Four major areas can be identified for the off-campus class model for the architecture pedagogy. They are:

(i) Live streaming

(ii) Live discourse

(iii) Pre-recorded lecture

(iv) Assignment and feedback

Live streaming and Live discourse belong to the online area. Live streaming is required for both theory and sessional courses. Live discourse is required to have discussion on student's work. Pre-recorded lecture is not suitable for sessional course. They may applicable for theory courses. Teacher can go through the assignment or works submitted by the students in an offline mode but need to give his feedback through a live discourse with the students (Fig. 9).

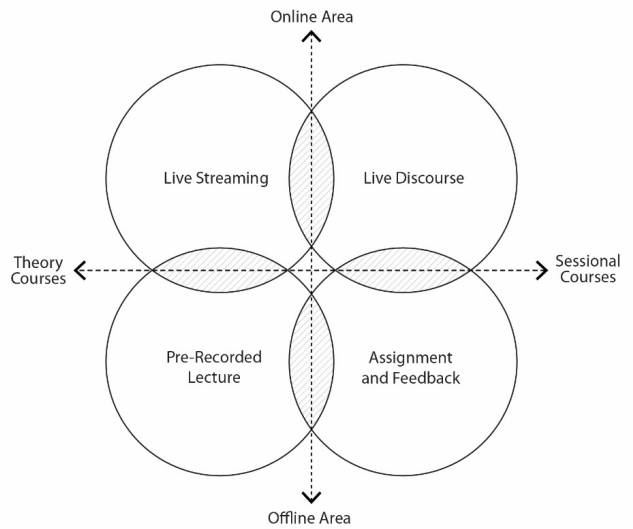

Figure 9: Four major areas of the off-campus class model

\section{Findings and Conclusion}

The world needs resilience and adaptability in this changing global environment - skills that are crucial to successfully move through this pandemic. In future, the university management should be able to work across demographic lines to maximize collective influence with successful coordination, by integrating imagination, connectivity and cooperation alongside empathy and egotistical intellect. The disruption associated with Corona virus will give educators time to rethink the field. Technology has broken down and will continue to play a significant role in educating future generations. The role of the instructor must also shift in a world where information is a mouse-click away.

Off-campus class is a new practice in architecture pedagogy in a developing country like Bangladesh. There are some challenges and limitations to cope up the model of off-campus class in architecture pedagogy. For those, who are accustomed to teaching face-to-face, this idea is unsettling, and both teachers and students are trying themselves to accustomed with online class day by day. Besides many easy to use softwares and mobile apps also developed to support the pedagogy. Students and teachers are also making themselves familiar with those to continue off-campus class smoothly.

There are, however, challenges to overcome. Some students without reliable internet access and/or technology struggle to participate in digital learning. Online learning needs hardware and software also. A desktop, laptop or a good android may be out of the reach of a poor family. Internet connection is another big issue. Broadband, Mobile data and Wi-Fi connections are very expensive and monthly fees may be daunting for the whole family. In many places of Bangladesh, there are many places without internet or very weak internet system. With Corona, where everyone is in a panic, it may be a question of whether they want to stay out of the house for a live class at certain times where there is a strong network. In live classes, the issue of student attendance, cyberbullying, uninterrupted internet access, security, video/ audio chat standards are come up. Absent of tangible model and drawings are also a big shortcoming for off-campus class.

Given the outbreak of the current Coronavirus pandemic and the suddenness with which it has managed to catch many-an-educational institution unprepared, the fact that these institutions have had to respond swiftly in terms of the continuous delivery of teaching and learning partly tells the successes and challenges encountered. In relation to the latter, a range of institutions have had a 
real stretch of both their material and people resources in order to deliver courses that were previously tailored/designed and formulated within a face-to-face format. This means that teachers, lecturers, instructors have had little, if no, time to adapt to the new delivery method coupled with having to learn new skills, competencies and capabilities in order to deliver the off-campus teaching and learning. In relation to the advantages, educational institutions have found innovative ways of delivery and the usefulness of latest technologies in facilitation of knowledge building and sharing.

One very important aspect of off-campus classes is the scope of motivation to the students by the teacher. Teachers need to be a motivator for his/her students during the pandemic period. As many students are dealing with COVID-19 patients within their family and many are sufferings from the consequences of such crisis, they need mental motivation which they can receive from their teacher through the offcampus class.

One must recognize that technology as a total alternative to the classroom has many limitations. Most teachers in universities in Bangladesh are not trained in distance education. In addition, both teachers and students have limitations on technology. It can be said that the off-campus class in Architecture pedagogy is still searching its own way with suitable methods and tools every day during this pandemic situation.

\section{References}

[1] J, Saavedra. Educational challenges and opportunities of the Coronavirus (COVID-19) pandemic. Worlds Bank Blogs, 2020. [Online] Available: https://blogs.worldba nk.org/education/educational-challengesand-opportunities-covid-19-pandemic [Accessed on $3^{\text {rd }}$ April 2020].

[2] S. Burgess and H. H. Sievertsen. Schools, skills, and learning. The impact of COVID-19 on education, VOX, 2020.

[3] P. Luthra and S. Mackenzie. 4 ways COVID-19 could change how we educate future generations. World Economic Forum, 2020. [Online] https:// www.wefor um.org/agenda /2020/03/4-ways-covid-19-education-future-generations/ [Accessed April 3, 2020].

[4] WEF. This is how The COVID-19 pandemic has changed education forever. World Economic Forum, 2020. [Online $]$ Available: https://www.weforum.org/agenda/2020 /04/coronavirus-education-global-covid 19online-digital-learning/ [Accessed on June 25, 2020].

[5] IAB. Accreditation Standard of Institute of Architects Bangladesh-2010. Institute of Architects Bangladesh, 2010.

[6] IAB. IAB Retrospect 2017-2018. Institute of Architects Bangladesh, 2018.

[7] UN. World Population Prospects 2019. Department of Economic and Social Affairs, United Nations, 2019. [Online] Available: https://population.un.org/wpp/ [Accessed April 4, 2020].

[8] GoB. Notice circulated by the Ministry of Education. Government of Bangladesh, 2020. [Online] Available: https://moedu. gov.bd/ [Accessed March 31, 2020]. 


\section{旬 CHITKARA}

\section{Journal on Today's Ideas - Tomorrow's Technologies}

Chitkara University, Saraswati Kendra, SCO 160-161, Sector 9-C, Chandigarh, 160009, India

Volume -8, Issue-1

June 2020

ISSN 2321-3906

Copyright: [ $\subset 2020$ Masud Ur Rashid] This is an Open Access article published in Journal on Today’s Ideas Tomorrow's Technologies by Chitkara University Publications. It is published with a Creative Commons Attribution- CC-BY 4.0 International License. This license permits unrestricted use, distribution, and reproduction in any medium, provided the original author and source are credited. 